\title{
Nitrato de prata e diferentes tipos de vedação na multiplicação in vitro de oliveira 'Arbequina'
}

\author{
Silver nitrate and different types of sealing on in vitro multiplication of 'Arbequina' olive tree
}

\author{
Lorena Pastorini Donini' Geórgea Soares Figueiredo ${ }^{\mathrm{II}}$ Márcia Wulff Schuch ${ }^{\mathrm{III}}$
}

\section{- NOTA -}

\section{RESUMO}

O tipo de tampa utilizado no frasco de cultura é um fator que irá determinar a qualidade do microambiente dentro dos frascos através das trocas gasosas com o ambiente externo. Devido à ação negativa do etileno nas culturas in vitro, há estudos sobre os inibidores de etileno, como o nitrato de prata, porém, não abordado na micropropagação da oliveira. Este trabalho teve como objetivo avaliar diferentes tipos de vedação e o efeito do nitrato de prata na multiplicação in vitro de oliveira. Para isso, foram utilizados segmentos nodais de plantas de oliveira cultivadas in vitro, com duas gemas e sem ápice. Os tratamentos constituíram-se de três tipos de vedação (tampa, papel alumínio e filme plástico) $e$ nitrato de prata (presença ou ausência) adicionado ao meio MO. Aos 60 dias, o material foi avaliado quanto ao número médio de brotações por explante, comprimento médio da brotação e número médio de folhas por brotação. Foi observado que, quando foram utilizados a tampa ou o papel alumínio, houve maior número de brotações. A utilização de papel alumínio como vedação proporcionou maior número de folhas e a utilização de nitrato de prata e a vedação com papel alumínio proporcionaram explantes de maior tamanho. Podese concluir que a utilização de papel alumínio como vedação e a adição de $10 \mathrm{mg}^{-1}$ de nitrato de prata ao meio de cultura MO apresenta melhores resultados na multiplicação in vitro de oliveira cv. 'Arbequina'.

Palavras-chave: micropropagação, Olea europaea, regulador de crescimento, $\mathrm{AgNO}_{3}$.

\section{ABSTRACT}

The type of cover used on the culture flask is the factor that will determine the microenvironment inside the flasks through gas exchange with external environment. Due the negative action of ethylene on in vitro cultures, there are many studies about ethylene inhibitors and one of them is the silver nitrate. This research aimed to evaluate different types of sealing and the effect of silver nitrate on in vitro multiplication of olive tree. Nodal segments of olive tree cultivated in vitro, with two buds and without apex were used. The treatments consisted in tree types of sealing (cover, aluminum and plastic film) and silver nitrate (presence or absence) added in the MO medium. On the $60^{\text {th }}$ day, it was assessed the average shoot number per explant, average shoot height and average leaves number per shoot. It was observed that the use of cover and aluminum provides higher number of shoots; the use of aluminum provides the largest average leaves number; the silver nitrate and sealing with aluminum provides longer size of explants. The use of aluminum as sealing and the addition of $10 \mathrm{mg} \mathrm{L}^{-1}$ of silver nitrate in the MO culture medium presents better results on in vitro multiplication.

Key words: micropropagation, Olea europaea, growth regulator, $\mathrm{AgNO}_{3}$.

O Brasil é um dos maiores importadores de produtos de oliveira da América do Sul, sendo a Argentina um dos maiores fornecedores, além da Espanha e Portugal (PIO et al., 2005; OLIVEIRA et al., 2001a). Essa espécie normalmente é propagada por estacas, no entanto, ainda não há um protocolo de propagação por estaquia definido (OLIVEIRA et al., 2009; OLIVEIRA et al., 2001b). Um aspecto fundamental

'Laboratório de Cultura de Tecidos, Embrapa Clima Temperado, 96010-971, Pelotas, RS, Brasil. E-mail: lorenadonini@yahoo.com.br. Autor para correspondência

"Fruticultura de Clima Temperado, Laboratório de Micropropagação de Plantas Frutíferas, Departamento de Fitotecnia, Faculdade de Agronomia Eliseu Maciel (FAEM), Universidade Federal de Pelotas (UFPel), Pelotas, RS, Brasil.

IIILaboratório de Micropropagação de Plantas Frutíferas, Departamento de Fitotecnia, FAEM, UFPel, Pelotas, RS, Brasil. 
para realizar a micropropagação de uma planta frutífera é o domínio da tecnologia de propagação em laboratório, o qual é o resultado de estudos realizados com os fatores que afetam o crescimento e o desenvolvimento das plantas in vitro (SCHUCH \& ERIG, 2005; SOUZA et al., 2008).

O microambiente dentro dos frascos de cultura parece ser um ambiente homogêneo, mas na verdade é um dos responsáveis pela variabilidade no comportamento das culturas, uma vez que os fatores determinantes para a qualidade do microambiente são os tipos de frasco, tipo de tampa e quantidade de meio presente (SOUZA et al., 2007).

O etileno é um gás regulador de crescimento produzido pelos vegetais que produz efeitos importantes e é de grande aplicação comercial, mas, no cultivo in vitro, a produção e ação desse gás afetam diretamente na resposta do explante, sendo ela positiva ou negativa (PASQUALet al., 2002). O ambiente fechado, ao qual os explantes são submetidos, proporciona, de modo geral, o acúmulo de etileno, que, mesmo em pequenas concentrações, pode ser fisiologicamente ativo e desencadear vários processos, dentre estes a abscisão foliar(NEPOMUCENO et al., 2007).

Devido à ação negativa do etileno nas culturas in vitro, há estudos sobre os inibidores de etileno (PASQUAL et al., 2002), um deles é o nitrato de prata $\left(\mathrm{AgNO}_{3}\right)$ que age inibindo a ação do etileno (ALKHAYRI \& AL-BAHRANY, 2001; OZDEN-TOKATLI et al., 2005). De acordo com GIRIDHAR et al. (2001), o uso de nitrato de prata tem efeito positivo nos estudos de multiplicação e enraizamento in vitro. Devido à falta de informações sobre a utilização do nitrato de prata na multiplicação in vitro da oliveira, este trabalho foi realizado com o objetivo de avaliar diferentes tipos de vedação e a adição de nitrato de prata na multiplicação in vitro de oliveira 'Arbequina'.

Para a realização deste estudo, foram utilizados segmentos caulinares com duas gemas, sem ápice e com aproximadamente $1 \mathrm{~cm}$ de comprimento, obtidos de brotações de plantas de oliveira 'Arbequina' cultivadas in vitro. $\mathrm{O}$ meio de cultura utilizado foi constituído pelos sais e vitaminas do MO (RUGINI, 1984), + 100mg L-1 de inositol + 30g L $\mathrm{g}^{-1}$ de sacarose + $2,19 \mathrm{~g} \mathrm{~L}^{-1}$ de glutamina, adicionados de $10 \mathrm{mg} \mathrm{L}^{-1}$ de nitrato de prata de acordo com o tratamento (com ou sem nitrato de prata). $\mathrm{O}$ pH $(5,8)$ foi ajustado antes da inclusão do ágar $(0,8 \%)$ e o meio foi autoclavado a $121^{\circ} \mathrm{Ce} 1,5 \mathrm{~atm}$ por 20 minutos. Foram utilizados frascos contendo $30 \mathrm{~mL}$ de meio de cultura. Após a inoculação, os explantes foram mantidos em sala de crescimento a $25 \pm 2^{\circ} \mathrm{C}$, fotoperíodo de 16 horas e densidade de fluxo de fótons de $27 \mathrm{mmol} \mathrm{m}^{-2} \mathrm{~s}^{-1}$.
Os tratamentos constituíram-se de três tipos de vedação (tampa de alumínio, tampa de papel alumínio e tampa de filme plástico) e nitrato de prata (presença ou ausência), num fatorial $3 \times 2$, totalizando seis tratamentos. O delineamento experimental utilizado foi inteiramente casualizado com quatro repetições por tratamento, em que cada repetição constituiu-se de um frasco contendo quatro explantes cada. Aos 60 dias de cultivo, o material foi avaliado quanto ao número médio de brotações, comprimento médio das brotações e número de folhas/brotação. Os dados foram submetidos à análise de variância e as médias dos tratamentos comparadas estatisticamente pelo teste de Duncan através do programa estatístico SANEST (ZONTA\& MACHADO, 1987).

O desdobramento das médias pelo teste de Duncan mostrou que, para número de brotações, quando foram utilizadas a tampa de metal ou tampa de papel alumínio, houve maior número de brotações $(1,86$ brotações), não diferindo entre si. Para número de folhas, a utilização de tampa de papel alumínio como vedação proporcionou maiores médias ( 8,57 folhas) (Tabela 1). Para comprimento médio de brotação, a utilização de nitrato de prata e a vedação com tampa de papel alumínio proporcionaram brotações de maior tamanho $(1,32 \mathrm{~cm})$, sendo superiores aos demais tratamentos (Tabela 1).

Observou-se que os explantes cultivados em frascos com vedação com tampa de filme plástico secaram e consequentemente morreram. Isso se deve ao fato de o meio de cultura ter secado, independente da adição ou não do nitrato de prata. No material mantido em frasco com tampa de metal, também foi observado que o meio de cultura secou, no entanto, os explantes sobreviveram. O único tratamento com tampa que não provocou a desidratação do meio de cultura foi o com a tampa de papel alumínio.

$\mathrm{Na}$ multiplicação in vitro de framboeseira e amoreira, LEITZKE (2007) observou que a utilização de papel alumínio proporcionou maior número de brotações para amoreira, não apresentando diferenças com a utilização de papel alumínio e filme plástico. No presente trabalho, o papel alumínio também proporcionou bons resultados, mas a utilização do filme plástico propiciou os piores resultados durante a multiplicação in vitro de oliveira 'Arbequina'. CUZZOL et al. (1996) observaram ótima sobrevivência de plantas aclimatizadas de Dianthus caryophyllus e atribuem o sucesso da aclimatização à condição de baixa umidade durante o cultivo in vitro oferecida pela vedação do tipo tampas de algodão.

No presente trabalho, pode-se observar que, mesmo não havendo diferenças para número de 
Tabela 1 - Número médio de brotações, folhas por brotação e comprimento médio das brotações $(\mathrm{cm})$ de explantes multiplicados de oliveira (Olea europaea L.) 'Arbequina' em meio de cultura com presença ou ausência de nitrato de prata e diferentes tipos de vedação.

\begin{tabular}{lcc}
\hline Vedação & Número de brotações & Número de folhas \\
\hline Tampa & $1,86 \mathrm{a}$ & $5,76 \mathrm{~b}$ \\
Alumínio & $1,86 \mathrm{a}$ & $8,57 \mathrm{a}$ \\
Filme plástico & $0,09 \mathrm{~b}$ & $0,28 \mathrm{c}$ \\
& -----Comprimento das brotações $(\mathrm{cm})----$ \\
& Com nitrato & Sem nitrato \\
Tampa & $0,64 \mathrm{~b} \mathrm{~A}$ & $0,53 \mathrm{a} \mathrm{A}$ \\
Alumínio & $1,32 \mathrm{a} \mathrm{A}$ & $0,74 \mathrm{a} \mathrm{B}$ \\
Filme plástico & $0,00 \mathrm{c} \mathrm{A}$ & $0,12 \mathrm{~b} \mathrm{~A}$ \\
\hline
\end{tabular}

Médias seguidas de mesma letra minúscula na coluna não diferem entre si pelo teste e Duncan em nível de 5\% de probabilidade de erro.

brotações e para número de folhas, a adição de nitrato de prata $\left(10 \mathrm{mg} \mathrm{L}^{-1}\right)$ associado à vedação com papel alumínio proporcionou maior comprimento das brotações. Resultados semelhantes foram obtidos por NEPOMUCENO et al. (2007) ao avaliarem dois tipos de inibidores de etileno no cultivo in vitro de angico. Eles observaram que, quando utilizaram $5 \mu \mathrm{M}$ de nitrato de prata no meio de cultura, este promoveu maior número de gemas e maior número de brotações. Já quando utilizaram concentração maior, de $10 \mu \mathrm{M}$, observaram maior número de folhas.

$\mathrm{Na}$ multiplicação in vitro de Vanilla planifolia, GIRIDHAR et al. (2001) observaram efeito positivo da adição de $20 \mu \mathrm{M}$ de nitrato de prata ao meio de cultura, promovendo maior número de brotações ( 5,6 brotações) e aumento no tamanho das brotações. GOH et al. (1997), durante a micropropagação de Garcinia mangostana, observaram que a adição de nitrato de prata nas concentrações de 10 e $20 \mu \mathrm{M}$ promoveu aumento significante no número de brotos regenerados. Em trabalho realizado com pistache, OZDEN-TOKATLI et al. (2005) observaram que a adição de $48 \mu \mathrm{M}$ de nitrato de prata proporcionou aumento da frequência de formação de brotações $(83,3 \%)$, quando comparado ao tratamento controle.

A utilização de nitrato de prata como inibidor da ação do etileno pode ter uma resposta variada no cultivo in vitro. Em algumas espécies, pode estimular a proliferação de calos, regeneração de brotos e a embriogênese somática, porém, em outras espécies, pode inibir a ação do etineo (AL-KHAYRI \& ALBAHRANY, 2001).

De acordo com os resultados obtidos na presente pesquisa, pode-se concluir que a utilização de papel alumínio como vedação e a adição de $10 \mathrm{mg} \mathrm{L}^{-1}$ de nitrato de prata ao meio de cultura MO apresentam melhores resultados na multiplicação in vitro de oliveira cultivar 'Arbequina'.

\section{REFERÊNCIAS}

AL-KHAYRI, J.M.; AL-BAHRANY, A.M. Silver nitrate and 2isopentyladenine promote somatic embryogenesis in date palm (Phoenix dactylifera L.). Scientia Horticulturae, v.89, p.291-298, 2001.

CUZZOL, G.R.F. et al. Enraizamento de cravo (Dianthus caryophyllus L.) in vitro e ex vitro. Scientia Agrícola, Piracicaba, v.53, n.1, p.60-66, 1996. Disponível em: <http:// www.scielo.br/scielo.php? script=sci_arttext\&pid=S010390161996000100008>. Acesso em: 24 mar. 2011.

GIRIDHAR, P. et al. Silver nitrate influences in vitro shoot multiplication and root formation in Vanilla planifolia Andr. Current Science, v.81, n.9, p.1166-1170, 2001.

GOH, C.J. et al. The role of ethylene on direct shoot bud regeneration from magosteen (Garcinia mangostana L.) leaves cultured in vitro. Plant Science, v.124, p.193-202, 1997.

LEITZKE, L.N. Micropropagação fotoautotrófica de pequenas frutas com a utilização de luz natural. 2007. 88f. Dissertação (Mestrado em Agronomia)-Faculdade de Agronomia Eliseu Maciel, Universidade Federal de Pelotas, Pelotas, RS.

NEPOMUCENO, C.F. et al. Controle da abscisão foliar e morfogênese in vitro em culturas de Anadenanthera colubrina (Vell.) Brenan var. cebil (Griseb) Altschul. Revista Árvore, v.31, n.5, p.967-975, 2007. Disponível em: <http:// www.s c i e lo.br/s c i e 1 o.p h p ? p id = S $0100-$ $67622007000500021 \&$ script $=$ sci_arttext $>$. Acesso em: 25 mar.2011.

OLIVEIRA, M.C. et al. Enraizamento de estacas de duas cultivares de oliveira submetidas à aplicação de diferentes fertilizantes. Bragantia, v.69, n.1, p.99103, 2001a. Disponível em: <http://www.scielo.br/ scielo.php?script=sci_arttext\&pid=S00068705201000010001 $4 \& \operatorname{lng}=\mathrm{pt} \& \mathrm{nrm}=\mathrm{iso} \& \mathrm{t} \operatorname{lng}=\mathrm{pt}>$. Acesso em: $17 \mathrm{mar}$. 2011. doi: 10.1590/S0006-87052010000100014.

OLIVEIRA, M.C. et al. Enraizamento de estacas de oliveira submetidas a aplicação de fertilizantes orgânicos e AIB. Ciência e Agrotecnologia, v.34, n.2, p.337-344, 2001b. Disponível em: $<$ http://www.scielo.br/scielo.php?script=sci_arttext\&pid=S1413$70542010000200010 \& \operatorname{lng}=\mathrm{pt} \& \mathrm{nrm}=\mathrm{iso} \& \operatorname{tn} \mathrm{g}=\mathrm{pt}>$. Acesso em: 17 mar. 2011. doi: 10.1590/S1413-70542010000200010.

OLIVEIRA, A.F. et al. Estaquia de oliveira em diferentes épocas, substratos e doses de AIB diluído em $\mathrm{NaOH}$ e álcool. Ciência e Agrotecnologia, v.33, n.1, p.79-85, 2009. Disponível em: <http:/ $/ \mathrm{www}$. scielo.br/scielo.php? script=sci_arttext\&pid=S1413$70542009000100011 \& \operatorname{lng}=\mathrm{pt} \& \mathrm{nrm}=\mathrm{iso} \& \mathrm{t} \operatorname{lng}=\mathrm{pt}>$. Acesso em: 17 mar. 2011. doi: 10.1590/S1413-70542009000100011.

OZDEN-TOKATLI, Y. et al. In vitro response of pistachio nodal explants to silver nitrate. Scientia Horticulturae, v.106, p.415-426, 2005. 
PASQUAL, M. et al. Indução de calos em anteras de café (Coffea arabica L.) cultivadas in vitro. Ciência Agrotecnológica, v.26, n.1, p.71-76, 2002. Disponível em: <http://www.editora.ufla.br/site/_adm/upload/revista/26-1 2002_09.pdf>. Acesso em: 25 mar. 2011.

PIO, R. et al. Enraizamento de diferentes tipos de estacas de oliveira (Olea europaea L.) utilizando ácido indolbutírico. Ciência Agrotecnológica, v.29, n.3, p.562-567, 2005. Disponível em: <http://www.scielo.br/scielo.php?script=sci_arttext $\&$ pid $=$ S1413$70542005000300008 \& \operatorname{lng}=\mathrm{pt} \& \mathrm{nrm}=\mathrm{iso} \& \mathrm{t} \operatorname{lng}=\mathrm{pt}>$. Acesso em: 17 mar. 2011. doi: 10.1590/S1413-70542005000300008.

RUGINI, E. In vitro propagation of some olive (Olea europaea sativa L.) cultivars with different root-ability, and medium development using analytical data from developing shoots and embryos. Scientia Horticulturae, v.24, n.2, p.123-134, 1984. SCHUCH, M.W; ERIG. A.C. Micropropagação de plantas frutíferas. In: FACHINELlO, J.C. et al. (Eds.). Propagação de plantas frutíferas. Brasília: Embrapa Informação Tecnológica, 2005. p.155-173.

SOUZA, J.A. et al. Enraizamento in vitro do porta-enxerto de macieira M-9 em função da vedação, sacarose e material de suporte do meio de cultura. Scientia Agraria, v.8, n.2, p.161164, 2007.

SOUZA, J.A. et al. Tipos e concentrações de citocinina na multiplicação in vitro de pitangueira. Ciência Rural, v.38, n.7, p.2046-2048, 2008. Disponível em: <http://www.scielo.br/ scielo.php?pid=S0103-84782008000700040\&script=sci_arttext $>$. Acesso em: 24 mar. 2011.

ZONTA, E.P.; MACHADO, A.A. SANEST - Sistema de análise estatística para microcomputadores. Pelotas: DMEC/IFM/UFPel, 1987. 138p. 